\title{
Characterization of Solanum melongena Thioesterases Related to Tomato Methylketone Synthase 2
}

\author{
Vy Le Uyen Khuat ${ }^{1}$, Vi Thi Tuong Bui ${ }^{1}$, Huong Thi Diem Tran ${ }^{1}$, Nuong Xuan Truong ${ }^{1}$, \\ Thien Chi Nguyen ${ }^{2}$, Phuc Huynh Hanh Mai ${ }^{1}$, Tuan Le Anh Dang ${ }^{1}$, Hiep Minh Dinh ${ }^{3}$, \\ Hong Thi Anh Pham ${ }^{1}$ and Thuong Thi Hong Nguyen ${ }^{1, *}$ \\ 1 Faculty of Biology and Biotechnology, University of Science, Vietnam National University, \\ Ho Chi Minh City 700000, Vietnam \\ 2 VN-UK Institute for Research and Executive Education, University of Danang, Danang City 550000, Vietnam \\ 3 Agricultural Hi-tech Park, Ho Chi Minh City 700000, Vietnam \\ * Correspondence: nththuong@hcmus.edu.vn
}

Received: 15 June 2019; Accepted: 16 July 2019; Published: 18 July 2019

\begin{abstract}
Methylketones are involved in plant defense and fragrance and have industrial applications as flavor additives and for biofuel production. We isolated three genes from the crop plant Solanum melongena (eggplant) and investigated these as candidates for methylketone production. The wild tomato methylketone synthase 2 (ShMKS2), which hydrolyzes $\beta$-ketoacyl-acyl carrier proteins (ACP) to release $\beta$-ketoacids in the penultimate step of methylketone synthesis, was used as a query to identify three homologs from S. melongena: SmMKS2-1, SmMKS2-2, and SmMKS2-3. Expression and functional characterization of SmMKS2s in E. coli showed that SmMKS2-1 and SmMKS2-2 exhibited the thioesterase activity against different $\beta$-ketoacyl-ACP substrates to generate the corresponding saturated and unsaturated $\beta$-ketoacids, which can undergo decarboxylation to form their respective 2-methylketone products, whereas SmMKS2-3 showed no activity. SmMKS2-1 was expressed at high level in leaves, stems, roots, flowers, and fruits, whereas expression of SmMKS2-2 and SmMKS2-3 was mainly in flowers and fruits, respectively. Expression of SmMKS2-1 was induced in leaves by mechanical wounding, and by methyl jasmonate or methyl salicylate, but SmMKS2-2 and SmMKS2-3 genes were not induced. SmMKS2-1 is a candidate for methylketone-based defense in eggplant, and both SmMKS2-1 and SmMKS2-2 are novel MKS2 enzymes for biosynthesis of methylketones as feedstocks to biofuel production.
\end{abstract}

Keywords: $\beta$-ketoacids; 2-methylketones; methylketone synthase 2; methyl jasmonate; methyl salicylate; Solanum melongena; thioesterase

\section{Introduction}

Methylketones are plant metabolites that have strong insecticidal activity against a wide range of anthropod insects [1] and are also assumed to contribute to the fragrance and flavor of fruits [2,3]. Recently, methylketones have also received interest as potential feedstocks to biofuel production $[4,5]$. The carbon skeletons for the synthesis of methylketones come from the fatty acid biosynthetic pathway. Until now, two methylketone synthase enzymes involved in methylketone biosynthesis, namely methylketone synthase 2 (MKS2) and methylketone synthase 1 (MKS1), have been functionally characterized in wild tomato species Solanum habrochaites subsp. glabratum [6]. Since the first functional characterization of the wild tomato Solanum habrochaites methylketone synthase 2 (ShMKS2) as a $\beta$-ketoacyl-acyl carrier proteins (ACP) thioesterase that catalyzes the penultimate step of the methylketone biosynthetic pathway, homologs of ShMKS2 have been isolated in the cultivated tomato Solanum lycopersicum and in the model plant Arabidopsis thaliana. All of them could also hydrolyze fatty 
acyl-ACP and/or $\beta$-ketoacyl-ACP substrates to release fatty acids or $\beta$-ketoacids, respectively $[6,7]$. $\beta$-Ketoacids are unstable and can readily undergo the non-enzymatic elimination of carbon dioxide under some conditions to form 2-methylketone decarboxylated products [8]. Decarboxylation of $\beta$-ketoacids could also be accelerated by an enzyme possessing decarboxylase activity such as methylketone synthase 1 (MKS1) present in the S. habrochaites glands. Methylketones are found in large quantities in the trichomes of this wild tomato species but are present at low levels in the cultivated tomato. Little is known about the methylketone accumulation, and the enzymes involved, in other Solanaceae species.

Interestingly, those plant-derived MKS2s, also known as acyl-lipid thioesterases (ALTs), generated different fatty acid and $\beta$-ketoacid profiles when recombinantly expressed in E. coli $[6,7,9]$. None of them shared the same catalytic profile in E. coli. Several ALT-like enzymes produced the same primary products but different minor products, others generated the same types but different ratios of products. In view of such broad catalytic diversity within the characterized MKS2/ALTs, screening for additional MKS2/ALT-like thioesterases from a wide range of plant species will likely diversify the enzyme collection and provide us with valuable input to gain insight into how the catalytic divergence happened in this enzyme family.

The Solanaceae family includes many species that have important roles in agriculture and medicine. Genome sequences of several species in this family have been determined for studies at molecular and cellular levels such as those of tomato (Solanum lycopersicum) [10], potato (Solanum tuberosum) [11], eggplant (Solanum melongena) [12], pepper (Capsicum annuum) [13,14], and tobacco (Nicotiana tabacum) [15]. Eggplant is one of the most popular vegetables in Asia, the Middle East, Southern Europe and Africa [16]. While the genetics of many agronomically important traits of tomato and potato has been extensively studied, the same is not true for the eggplant. It is noteworthy that eggplant (S. melongena L.) is a representative of the Leptostemonum clade, the largest monophyletic group in the Solanaceae family. Eggplant rose in Africa and were dispersed throughout the Middle East to Asia, while most important plants in Solanaceae, such as tomatoes, potatoes, peppers and tobacco originated in the Americas [17]. The accumulation of genetic information of eggplant thus will be valuable for comparative biological studies of genetics, physiology, development, and evolution of the Solanaceae family. Recently, the eggplant genome was substantially determined [12], and a draft genome sequence of S. melongena was built and uploaded on https://solgenomics.net/. In addition, the Eggplant Genome Consortium has released a pre-publication version of their eggplant genome on http://www.eggplantgenome.org. These would be an excellent source for prospecting novel genes in this species.

We initiated a study of 2-methylketone synthesis in S. melongena L. to investigate the contribution of these compounds in insect resistance, fragrance and flavor in the crop plant, and also a possible biofuel blending agents. Here, we report the partial characterization of three thioesterases from $S$. melongena $\mathrm{L}$. that are related to tomato methylketone synthase 2.

\section{Materials and Methods}

\subsection{Plant Growth and Treatment Conditions}

Seeds of eggplant (Solanum melongena L.) were obtained from the Southern Fruit Research Institute (SOFRI), Vietnam.

For the isolation of full-length cDNAs of eggplant MKS2 genes and determination of tissue specific gene expression, 13-week-old eggplant plants were dissected to obtain material of each of the following tissues: young leaves, mature leaves, roots, stems, flowers, and fruits.

For stress treatments, plants were grown in a greenhouse under the same conditions of temperature and light. The six-week-old plants were used for different stress treatments. Wounding was performed by crushing eggplant leaves two times across the midvein with a hemostat, and leaves were collected for analysis after $24 \mathrm{~h} \mathrm{[18].} \mathrm{For} \mathrm{the} \mathrm{methyl} \mathrm{jasmonate} \mathrm{(MeJA)} \mathrm{treatment,} \mathrm{each} \mathrm{intact} \mathrm{plant} \mathrm{was} \mathrm{enclosed}$ 
in a 4-L airtight glass container with one $1-\mathrm{cm}^{2}$ piece of filter paper carrying $6.6 \mu \mathrm{L}$ (or $6.8 \mathrm{mg}$ ) of MeJA. All the plants exposed to MeJA vapor for $2 \mathrm{~h}$ were further grown in the greenhouse for $24 \mathrm{~h}$ before their leaves were collected for gene expression analysis [19]. Methyl salicylate (MeSA) treatment was conducted using similar experimental setting of the MeJA treatment experiment, in which $2.53 \mu \mathrm{L}$ (or $3 \mathrm{mg}$ ) of MeSA was applied onto a 1- $\mathrm{cm}^{2}$ piece of filter paper [20]. Untreated plants were used as control for each experiment. All experiments were repeated three times, each time with three biological replicates. Leaves were sampled and immediately frozen in liquid nitrogen and stored at $-80{ }^{\circ} \mathrm{C}$.

\subsection{Identification of SmMKS2 Genes in the Eggplant Genome}

The amino acid sequence of ShMKS2 protein (Genbank accession: ADK38536.1) was used as a query in a translated basic local alignment search tool (TBLASTN) search against the Eggplant Genome Database (http://eggplant.kazusa.or.jp) to identify scaffolds that contain the MKS2 homologs, designated as SmMKS2s. The FGENESH gene finder program (http://www.softbery.com) [21] was used for initial annotation of the predicted eggplant MKS2 genes.

\section{3. cDNA Isolation and Phylogenetic Analysis of SmMKS2 Sequences}

The total RNA was isolated from the collected tissues and converted to cDNA using ProtoScript ${ }^{\circledR}$ II First Strand cDNA Synthesis kit (New England Biolabs, Massachusetts, USA) and oligo (dT) 18 primer. Full-length cDNA sequences for $S m M K S 2 s$ were obtained by polymerase chain reaction (PCR) using $1 \mu \mathrm{L}$ of the resulting cDNA and gene-specific primers (Supplementary File 8). The PCR products were purified using Expin ${ }^{\mathrm{TM}}$ Gel SV (GeneAll Biotechnology Co., Ltd., Seoul, Korea) and cloned into pGEM-T Easy cloning vector (Promega, Wisconsin, USA). The recombinant plasmids were transformed into E. coli TOP10 competent cells. Positive clones were selected by blue/white colony screening and PCR colony. Recombinant plasmids were extracted using StrataPrep Plasmid Miniprep Kit (Agilent Technologies, California, USA) and their inserts were sequenced. Three SmMKS2 sequences have been deposited in GenBank with accession number MK990608, MK990609, and MK990610, respectively. Phylogenetic and molecular evolutionary analyses were conducted using MEGA X [22].

\subsection{Gene Expression Analysis by Quantitative Real-Time Polymerase Chain Reaction (qRT-PCR)}

Total RNA was isolated from the described tissues using the Ribospin ${ }^{\mathrm{TM}}$ Plant kit (GeneAll Biotechnology Co., Ltd., Seoul, Korea) according to the manufacturer's instructions. The isolated RNA was treated with RNase-free DNase I (Thermo Scientific, Massachusetts, USA) to remove genomic DNA contamination. The integrity of the extracted RNA was assessed by agarose gel electrophoresis. One and a half $\mu \mathrm{g}$ of DNA-free RNA was reverse transcribed using ProtoScript ${ }^{\circledR}$ II First Strand cDNA Synthesis (New England Biolabs, Massachusetts, USA) and oligo (dT) 18 primer. Gene-specific primers were designed using OligoAnalyzer 3.1 (Integrated DNA Technologies, Inc., Iowa, USA) and Primer-BLAST program provided by the National Center for Biotechnology Information (NCBI) (Supplementary File 8). Quantitative real-time PCR was performed with CFX96 Touch Real-Time PCR Detection System (Bio-Rad Laboratories, Inc., California, USA) using SolGent $h$-Taq DNA Polymerase (SolGent, Daejeon, Korea) and EvaGreen DNA-binding Dye (Biotium, California, USA) according to the manufacturer's instructions. The cDNA was diluted from 1:5 to 1:100, and $2 \mu \mathrm{L}$ was subjected to each quantitative real-time polymerase chain reaction (qRT-PCR) in a final volume of $12.5 \mu \mathrm{L}$ containing 1X SolGent $h$-Taq Reaction Buffer, 0.5X EvaGreen, $2.5 \mathrm{mM} \mathrm{MgCl}, 0.2 \mathrm{mM} \mathrm{dNTP,} 0.3 \mathrm{U} h$-Taq polymerase, $400 \mathrm{nM}$ each for forward and reverse primers. The amplification parameters were one cycle at $95{ }^{\circ} \mathrm{C}$ for $15 \mathrm{~min}, 40$ cycles of $95^{\circ} \mathrm{C}$ for $20 \mathrm{~s}, 55^{\circ} \mathrm{C}$ for $40 \mathrm{~s}$, and $72{ }^{\circ} \mathrm{C}$ for $7 \mathrm{~s}$. Transcript levels of SmMKS2-1, SmMKS2-2 and SmMKS2-3 were analyzed by qRT-PCR using gene-specific primers (Supplementary File 1), normalized to the eggplant reference gene adenine phosphoribosyl transferase (APRT) (Genbank accession: JX448345.1) and expressed as relative expression [23]. Each data point represents an average of at least three independent biological samples with three technical replicates for each sample. 


\subsection{Expression of SmMKS2-1, SmMKS2-2 and SmMKS2-3 in E. coli}

The coding regions of SmMKS2-1, SmMKS2-2, and SmMKS2-3 genes (minus the transit peptide encoding region) were amplified by Phusion High Fidelity DNA Polymerase (Thermo Scientific, Massachusetts, USA) to add NdeI and XhoI restriction sites, spliced into pETDuet-1 (Invitrogen, California, USA), and transformed into E. coli strain C41(DE3) (Invitrogen). The E. coli C41(DE3) cells containing the plasmid pETDuet-1-SmMKS2- $x(x=1 / 2 / 3)$ was grown in Terrific Broth (TB) medium containing $100 \mu \mathrm{g} / \mathrm{mL}$ ampicillin until an $\mathrm{OD}_{600 \mathrm{~nm}}$ reached 0.6 to 0.8 . Expression of the recombinant protein was induced by addition of $0.5 \mathrm{mM}$ isopropylthio- $\beta$-galactoside (IPTG) and the culture was kept at $18{ }^{\circ} \mathrm{C}$ for $16 \mathrm{~h}$. The cell cultures were collected for further analysis. A negative control experiment (E. coli C41(DE3) cells carrying the empty plasmid pETDuet-1) was performed in parallel.

For protein expression analysis, bacterial cells were harvested by centrifugation $\left(6000 \times g, 4{ }^{\circ} \mathrm{C}, 10\right.$ $\mathrm{min})$, and resuspended in the lysis buffer $(100 \mathrm{mM} \mathrm{NaCl} ; 10 \mathrm{mM}$ Tris; $1 \mathrm{mM}$ EDTA; $10 \%$ glycerol; $\mathrm{pH}$ 8). Cells were lysed by sonication and the total cell lysate was centrifuged $\left(22,000 \times g, 4{ }^{\circ} \mathrm{C}, 3 \mathrm{~min}\right)$ to pellet the cellular debris: the lysis supernatant was collected as the soluble protein fraction, and the pellet as the insoluble fraction. The pellet was then re-suspended in an equal volume of the lysis buffer. Samples of total cell lysate, soluble and insoluble protein fractions were boiled for $10 \mathrm{~min}$ at $98{ }^{\circ} \mathrm{C}$ in a reducing loading buffer $(0.1 \mathrm{M}$ Tris- $\mathrm{HCl}, \mathrm{pH} 6.8,1 \%$ sodium dodecyl sulfate (SDS), $10 \%$ glycerol, $0.003 \%$ bromophenol blue, and $1 \% \beta$-mercaptoethanol) [24] to denature proteins before they were loaded on the gel. Prepared samples were run through $4 \%$ stacking gel and 16\% separating gel in Tris-Tricine-SDS Buffer 1X (0.1 M Tris, 0.1 M Tricine and 0.1\% SDS, pH 8.25) [25] at a constant voltage of $90 \mathrm{~V}$. The gel was stained with Coomassie Blue.

For methylketone profile analysis, hexane was added to the cell culture of E. coli expressing SmMKS2 and the mixture was then incubated at $75{ }^{\circ} \mathrm{C}$ for $30 \mathrm{~min}$ to convert $\beta$-ketoacids into the corresponding 2-methylketones. After the extraction, the mixture was cooled at $18{ }^{\circ} \mathrm{C}$ for $10 \mathrm{~min}$, vortexed and centrifuged at 5,000 rpm for $10 \mathrm{~min}$. The gas chromatography-mass spectrometry (GC-MS) analysis was conducted by injecting $1 \mu \mathrm{L}$ of the resulting extract into an HP5 MS column $(30 \mathrm{~m} \times 0.25 \mathrm{~mm} \times 0.25 \mu \mathrm{m})$ installed on a gas chromatograph (Agilent $6890 \mathrm{~N})$ coupled to an Agilent 5972 Mass Spectrum Detector. Helium was used as the carrier gas at a constant flow rate of $1 \mathrm{~mL} / \mathrm{min}$. The MS was operated in SCAN mode and molecular ions were typically scanned from 40 to 500 atomic mass units. The injector was programmed to hold at $250{ }^{\circ} \mathrm{C}$ for $0.5 \mathrm{~min}$, ramp to $280{ }^{\circ} \mathrm{C}$ at $50{ }^{\circ} \mathrm{C} / \mathrm{min}$, and hold for $1 \mathrm{~min}$. The column oven was programmed to initialize at $60^{\circ} \mathrm{C}$, hold for 5 min, then ramp to $300{ }^{\circ} \mathrm{C}$ at a rate of $15^{\circ} \mathrm{C} / \mathrm{min}$. For saturated methylketones, peaks identified as 2-heptanone, 2-nonanone, 2-undecanone, and 2-tridecanone by the similarity search in NIST 14 MS Search program were further confirmed by comparing their retention times with those of 2-methylketone standards (Sigma-Aldrich). For monounsaturated ketones, as no authentic standards were available, peaks were identified based on their previously reported mass spectrum [4,7]. Quantification of methylketones was performed as previously described [6].

\subsection{Accession Numbers}

The GenBank accession numbers for the sequences referred to in this paper are given in parentheses: SmMKS2-1 (MK990608), SmMKS2-2 (MK990609) and SmMKS2-3 (MK990610).

\subsection{Data Analysis}

In order to study the effect of wounding, MeJA, and MeSA on the transcriptional expression of SmMKS2 genes, we first used one-way analysis of variance (ANOVA) and then assessed significant difference between treated plants and control plants by Dunnett's post hoc comparisons. 


\section{Results}

\subsection{Identification of MKS2 Genes in S. melongena}

TBLASTN searches with the known wild tomato ShMKS2 protein sequence against the Eggplant Genome Database identified three scaffolds (Sme2.5_06004.1,Sme2.5_20884.1, and Sme2.5_02928.1) with an e-value lower than $2 \times 10^{-52}$, each of which contained DNA fragments encoding amino acid sequences with significant similarity to different subregions of the ShMKS2 protein. Three putative open reading frames with high identity to ShMKS2 were predicted from the identified scaffolds, and designated as SmMKS2-1, SmMKS2-2, and SmMKS2-3, respectively.

Isolation of cDNA and genomic sequences corresponding to SmMKS2 genes was performed by PCR using primers that were designed based on the predicted open reading frames (ORFs). Subsequent sequencing and alignment of the cDNA sequence to genomic sequence revealed that SmMKS2-1 spanned approximately 4364 bp on eggplant scaffold Sme2.5_06004.1 and consisted of five exons. The complete coding region of SmMKS2-1 gene is $618 \mathrm{bp}$ long and encodes a 205 amino acid protein (23.4 kDa) (Supplementary Files 1 and 2).

While the released draft eggplant genome sequence suggested that $S m M K S 2-2$ is present in the scaffold Sme2.5_20884.1, the incomplete and erroneous assembly of this scaffold is likely the cause of our initial failure in isolating the full-length cDNA sequence of SmMKS2-2 using primers based on the predicted SmMKS2-2 ORF. Initially, the longest cDNA of SmMKS2-2 we could obtain was 426 bp long and the first ATG codon of the open reading frame in this cDNA was equivalent to the ATG codon that occurs in positions 2 to 4 of exon 2 in the SmMKS2-1 genes (Supplementary Files 2 and 3 ). In order to determine the beginning of the transcript of SmMKS2-2, we performed TBLASTN searches against Transcriptome Shortgun Assembly (TSA) database of Solanum (taxid:4107) using the amino acid sequence deduced from the 426-bp cDNA segment of SmMKS2-2 as a query and identified a homologous sequence from S. prinophyllum (accession: GEZT01051720.1) with the highest amino acid sequence identity (91\%). This sequence shared 100\% identity with the first 159 residues of the query sequence and thus was utilized as a framework for designing forward primer to retrieve the $5^{\prime}$-end of SmMKS2-2 cDNA. A PCR experiment was performed using the above-designed forward primer and a reverse primer complementary to the $3^{\prime}$ end of the coding region. Analysis of the DNA fragments produced in this experiment by agarose gel electrophoresis gave a sharp band (Supplementary File 1). Subsequent sequencing of the resulting fragment indicated that the SmMKS2-2 transcript was 180 nucleotides longer at its $5^{\prime}$ ends than the initially isolated cDNA. As a result, the full-length cDNA sequence of SmMKS2-2 obtained from eggplant flower tissue was 606 bp long and encodes for a 22.5-kDa protein of 201 amino acids. The newly uncovered $5^{\prime}$ end sequence was homologous to exon 1 in the SmMKS2-1 gene, which encodes a putative N-terminal transit peptide as seen in all other known homologous genes from Arabidopsis and tomato. The complete genomic sequence of SmMKS2-2 gene was determined and shown in Supplementary File 3. The SmMKS2-2 gene is 3424 bp long and has five exons and four introns.

Amplification of the SmMKS2-3 cDNA by RT-PCR using primers that are complementary to the $5^{\prime}$ and $3^{\prime}$ end of the predicted full-length ORFs on the eggplant scaffold Sme2.5_02928.1 gave a sharp band (Supplementary File 1). Sequencing the resulting fragment showed that SmMKS2-3 contains an in-frame stop codon in exon 4 in addition to a 47-nucleotide insertion at the end of the third exon that is predicted to cause a frameshift. SmMKS2-3 has a GT to GC transition at nucleotides 40ß-404 (this dinucleotide corresponds to the 5' splice site of intron 3 in SmMKS2-1 and SmMKS2-2) and as a result, the new $5^{\prime}$ splice site shifted 47 nucleotides to the right in the SmMKS2-3 sequence compared to SmMKS2-1 and SmMKS2-2 sequences. The insertion of 47 intronic nucleotides into the SmMKS2-3 transcript results in a frameshift that leads to a premature stop codon within the fourth exon (Supplementary File 4). Thus, the SmMKS2-3 gene has only four exons and three introns and encodes a smaller protein of 156 amino acids $(17.1 \mathrm{kDa})$. 


\subsection{Phylogenetic Analysis of the Eggplant SmMKS2s}

A multiple sequence alignment of the SmMKS2 sequences and a subset of the homologous proteins showed that the eggplant sequences included a conserved aspartate (Asp) required for the catalytic activity of single Hotdog fold thioesterases (Figure 1). The Asp residue was located at position 17 in the 4-hydroxybenzoyl-CoA thioesterase (4HBT) from Pseudomonas sp. strain CBS and previously identified as the catalytic residue required for thioester bond cleavage [26]. In line with this, conversion of the equivalent aspartate to alanine abolished the thioesterase activity of ShMKS2 and ALT1 [6,7]. In addition, the full-length amino acid sequence of SmMKS2-1 and SmMKS2-2 also contained a C-terminal Hotdog-fold superfamily domain, a typical domain of single Hotdog fold acyl-ACP thioesterases found in different plant taxa [6,7]. Based on the amino acid sequence, thioesterases have been divided into 23 different families and the plant MKS2 proteins belong to the thioesterase family 9 (TE9) [27]. Structural characterization of YbgC thioesterases in TE9 [27,28] and

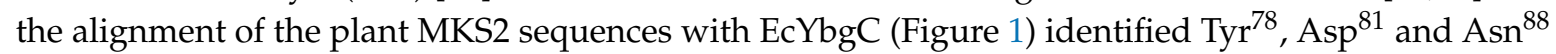
(numbered relative to the sequence of SmMKS2-1) as the most likely candidates for catalytic triad residues of the plant MKS2s. Notably, SmMKS2-3 also contained the putative catalytic triad, but lost 37 residues in the C-terminal region of Hotdog domain because of the presence of a premature termination codon (Figure 1).

To investigate the phylogenetic relationship of $S m M K S 2$ genes with single Hotdog fold thioesterase genes found in other species, a phylogenetic analysis based on the coding sequences of MKS2s from several Solanaceace plant species (Solanum melongena, Solanum habrochaites, Solanum lycopersicum, Nicotiana tabacum, Capsicum annuum, Solanum tuberosum), as well as representative MKS2 sequences from bacteria (E. coli and Pseudomonas), algae (Chlamydomonas reinhardtii), lycophytes (Selaginella moellendorffii), monocots (Oryza sativa), and dicots (Arabidopsis thaliana) was built using the maximum likelihood method. The phylogenetic tree makes clear that all the Solanaceae MKS2 genes form a distinct clade that diverged from AtALT genes. ShMKS2 and SIMKS2c form a separate branch, and all SmMKS2 genes are located on a parallel branch together with other Solanaceae MKS2 genes. SmMKS2-2 appears to be distinct but closely related to other Solanaceae MKS2 genes (Figure 2). A second analysis of these genes based on Bayesian inference was also conducted (Supplementary File 5), and it generated essentially the same phylogenetic tree, but with much higher bootstrap values to some branch points in the clade included MKS2 genes from the Solanaceae species. 


Ps4HB
EcYBGC
AT1G35250_AtALT
AT1G35290_AtALT
AT1G68260_AtALT
AT1G68280_AtALT
SmMKS2-2
SmMKS2-3
ShMKS2
S1MKS2c
S1MKS2b
S1MKS2a
SmMKS2-1

Ps4HB
EcYBGC
AT1G35250_AtALT
AT1G35290_AtALT
AT1G68260_AtALT
AT1G68280_AtALT
SmMKS2-2
SmMKS2-3
ShMKS2
S1MKS2c
S1MKS2b
S1MKS2a
SmMKS2-1

Ps 4HB

ECYBGC

AT1G35250 AtALT

AT1G35290_AtALT AT1G68260 AtALT AT1G68280_AtALT

SmMKS2-2

SmMKS2-3

ShMKS2

SIMKS2c

SIMKS2b

SIMKS2a

SmMKS2-1

PS4HB
ECYBGC
AT1G35250_AtALT
AT1G35290_AtALT
AT1G68260_AtALT
AT1G68280_AtALT
SmMKS2-2
SmMKS2-3
ShMKS2
S1MKS2c
S1MKS2b
S1MKS2a
SmMKS2-1
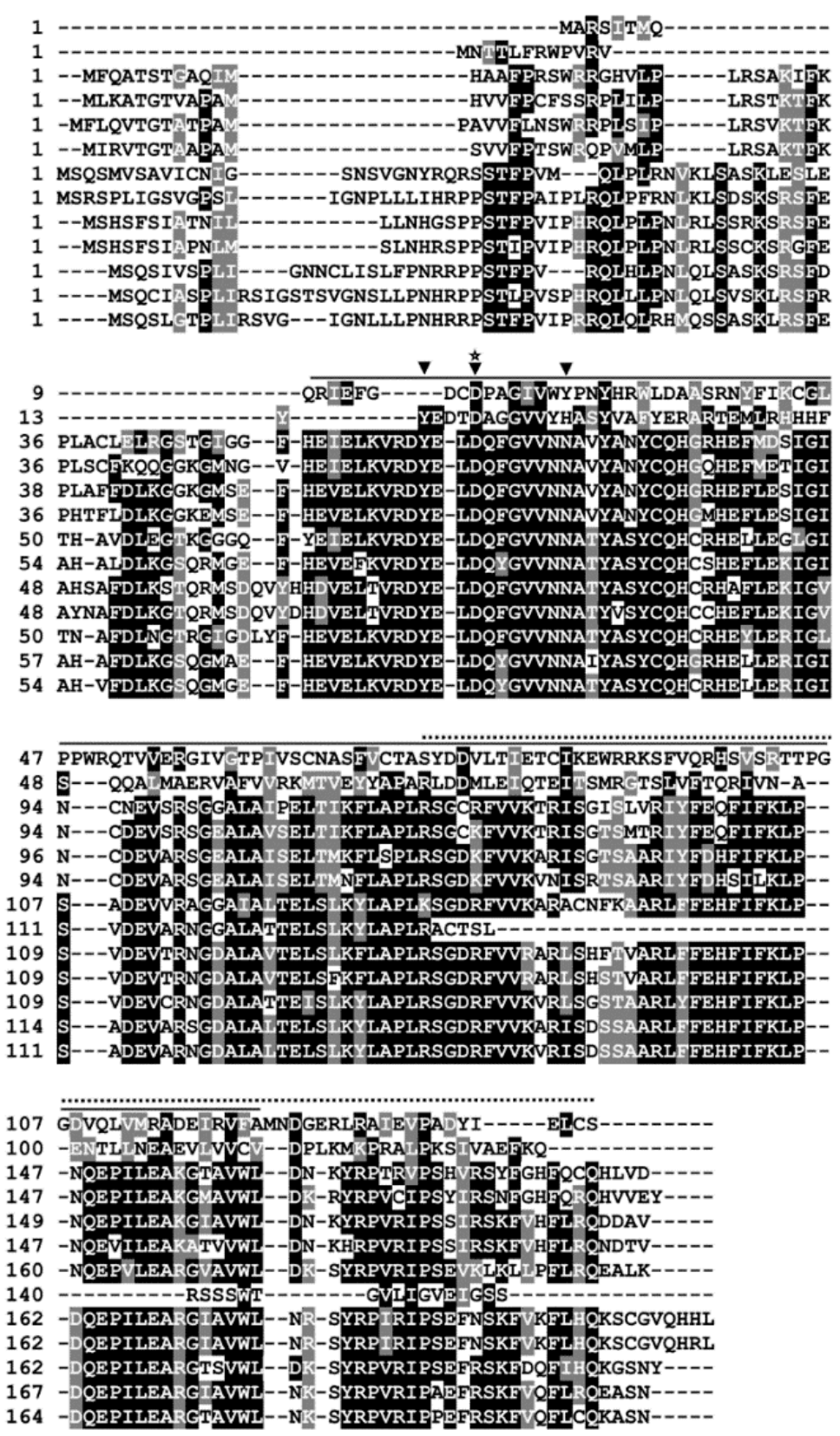

Figure 1. Amino acid sequence alignment of SmMKS2 with functionally characterized methylketone synthase 2/acyl-lipid thioesterases (MKS2/ALTs). The deduced amino acid sequences of SmMKS2-1, SmMKS2-2, and SmMKS2-3 are compared to previously reported At1g68260 (AEE34774.1), At1g68280 (AEE34776.2), At1g35290 (AEE31776.1), and At1g35250 (AEE31773.1) from A. thaliana, ShMKS2 (ADK38536.1) from the wild tomato Solanum habrochaites, SlMKS2a (ADK38541.1), SlMKS2b (ADK38542.1) and SlMKS2c (ADK38543.1) from the cultivated tomato Solanum lycopersicum, Ps4HB (EF569604) from Pseudomona, and EcYbgC from Escherichia coli. Identical residues are highlighted in black and similar residues are highlighted in grey. The arrowheads indicate positions of catalytic residues defined in members of the thioesterase family 9, including the structurally resolved $E c Y b g C$ from E. coli. The conserved Asp residue required for thioester bond cleavage is marked with star. Black horizontal line indicates the conserved Hotdog fold region present in MKS2/ALTs, and the dashed horizontal line indicates C-terminal residues lost in SmMKS2-3 and replaced by new amino acids encoded by 47 intronic nucleotides plus the first nucleotide of exon 4 . 


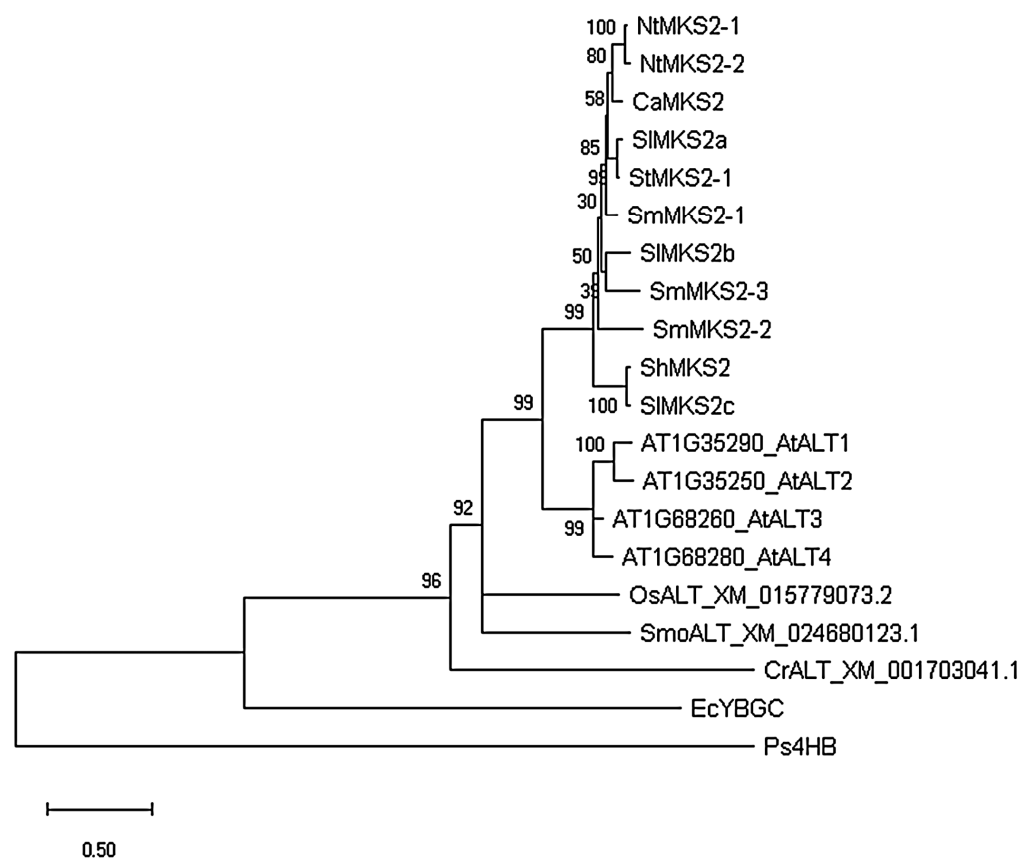

Figure 2. Phylogenetic analysis of $S m M K S 2$ genes. Maximum likelihood phylogenetic tree of the Solanaceae MKS2s and previously reported ALTs from A. thaliana and Ps4HB (EF569604) from Pseudomonas. Bootstrap values were performed with 1000 replicates and indicated next to the branches. At, Arabidopsis thaliana; Ca, Capsicum annuum; Nt, Nicotiana tabacum; Sh, S. habrochaites; Sl, S. lycopersicum; St, S. tuberosum; Os, Oryza sativa; Smo, Selaginella moellendorffii; Cr, Chlamydomonas reinhardtii; Ec, E. coli; Ps, Pseudomonas.

\subsection{SmMKS2 Genes are Differently Expressed in Various Eggplant Organs}

The mRNA expression of SmMKS2 in different eggplant organs was investigated by quantitative real-time polymerase chain reaction (qRT-PCR) analysis. Transcripts of SmMKS2-1 were detected in multiple plant tissues, both aerial and root parts, but were highest in leaves and fruits. The highest level of SmMKS2-2 transcripts was in flowers, with much lower but detectable levels in all other tissues tested. The expression pattern of SmMKS2-3 transcripts were detected only at very low levels in fruits. In the plant, the magnitude of SmMKS2-2 and SmMKS2-3 expression was much lower than that of SmMKS2-1 (Figure 3). 


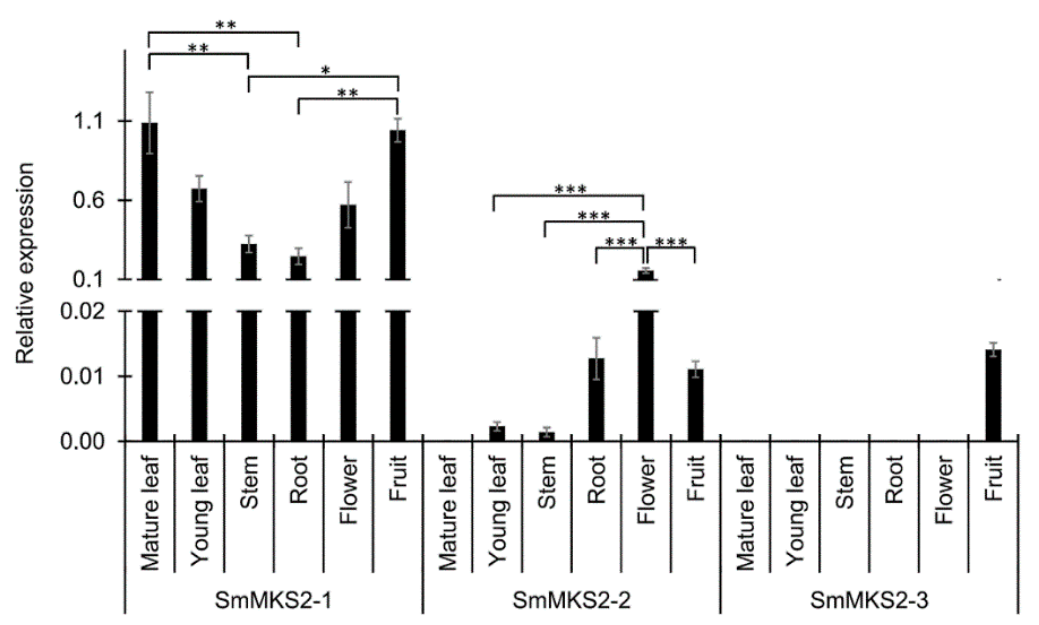

Figure 3. Spatial expression patterns of three $S m M K S 2$ genes in eggplant determined by quantitative real-time polymerase chain reaction (qRT-PCR) analysis. Transcript levels were normalized with respect to the adenine phosphoribosyl transferase gene (APRT, Genbank accession: JX448345.1). Values are mean \pm standard error (SE) from three replicates. Significant differences were assessed by one-way analysis of variance (ANOVA) followed by Tukey's test: ${ }^{*} p<0.01,{ }^{* *} p<0.005,{ }^{* * *} p<0.001$.

3.4. SmMKS2-1 but Neither SmMKS2-2 Nor SmMKS2-3 is Induced by Artificial Wounding, Methyl Jasmonate, and Methyl Salicylate

To assess whether SmMKS2 genes are involved in the regulation of stress responses in S. melongena, changes in their transcriptional expression in eggplant leaves upon artificial wounding, and exogenous application of MeJA and MeSA were analyzed by qRT-PCR (Figure 4). Transcriptional expression of SmMKS2-1 was indeed induced in leaves by these stress factors. Expression of SmMKS2-2 was not induced in leaves following mechanical wounding, or treatment with MeJA or MeSA for $24 \mathrm{~h}$. SmMKS2-3, which was undetectable in leaves (Figure 3), was not activated after treatment. Taken together, these results suggest that SmMKS2-1 might play a role in stress responses via MeJA- and MeSA-mediated signaling pathways in S. melongena.

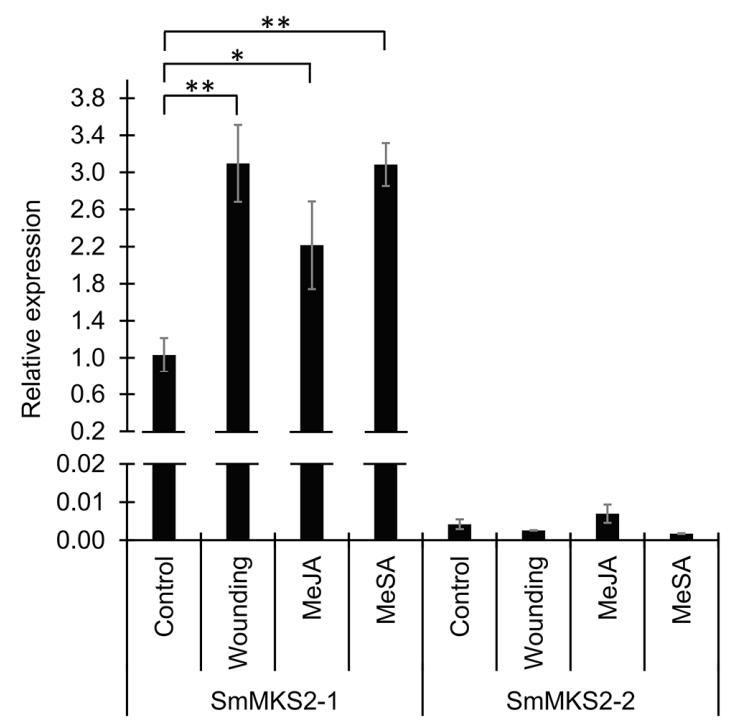

Figure 4. Expression profiles of $S m M K S 2-1$ and $S m M K S 2-2$ genes in response to wounding, MeJA and MeSA treatment. Values are means \pm SE from three replicates. Significant differences were assessed by a Dunnett's test: ${ }^{*} p<0.05,{ }^{* *} p<0.01$. 


\subsection{Expression of SmMKS2 Genes in E. coli Led to the Production of $\beta$-Ketoacids}

The expression of SmMKS2 proteins in E. coli C41(DE3) strain was verified by sodium dodecyl sulfate polyacrylamide gel electrophoresis (SDS-PAGE) gel analysis (Supplementary File 6). The SmMKS2 proteins were predominantly present in the soluble fractions prepared from E. coli cells harboring the recombinant plasmids but not in those transformed with the empty vector. Introduction of a premature termination codon into the fourth exon of the SmMKS2-3 gene leads to premature termination of translation and thus, the molecular weight of SmMKS2-3 appears to be lower than that of SmMKS2-1, or SmMKS2-2 in SDS-PAGE (Supplementary File 6).

Putative intermediates in the synthesis of the final methylketone products are $\beta$-ketoacids. The unstable nature of $\beta$-ketoacids provides considerable challenges to the effort to detect and quantify them directly. However, $\beta$-ketoacids could be decarboxylated by heat treatment or by enzymatic catalysis to form the corresponding 2-methylketones, which can be measured by gas chromatography-mass spectrometry [6]. Thus, in order to test whether expression of each SmMKS2 (without its transit peptide) in the E. coli C41(DE3) strain resulted in the formation of $\beta$-ketoacids, we collected cell culture of bacterial cells expressing each of them, and analysed for the presence of final methylketone products formed after the culture was treated with heat $\left(75^{\circ} \mathrm{C}\right)$ for $30 \mathrm{~min}$.

The culture of E. coli C41(DE3) cells expressing SmMKS2-1 released several types of odd-chain methylketones ranging from 7 to 17 carbons, including saturated methylketones such as 2-heptanone (7:0), 2-nonanone (9:0), 2-undecanone (11:0), 2-tridecanone (13:0), and 2-pentadecanone (15:0) and monosaturated methylketones such as (Z)-6-tridecen-2-one (13:1), (Z)-8-pentadecen-2-one (15:1), and putative 2-heptadecenone (17:1). Among them, (Z)-6-tridecen-2-one (13:1) was the most abundant product with $1391 \mathrm{ng} / \mathrm{OD}$ unit (Figure 5; Figure 6). SmMKS2-2 expression generated high levels of unsaturated medium-chain methylketone 13:1 (51,054 ng/OD unit) along with low levels of 2-undecanone (11:0) (6019 ng/OD unit) and 2-tridecanone (13:0) (5908 ng/OD unit), and even much lower levels of 2-nonanone (9:0) (348 ng/OD unit), (Z)-4-undecen-2-one (11:1) (705 ng/OD unit), and (Z)-8-pentadecen-2-one (15:1) (ng/mL). Levels of 13:1 methylketone produced by SmMKS2-2 were about 40 times higher than those produced by SmMKS2-1 (Figures 5 and 6). The structures of saturated methylketone products were confirmed by the similarity search in NIST 14 MS Search program and by comparing their retention times with those of 2-methylketone standards. Given no authentic monounsaturated 2-methylketones standards were available, (Z)-4-undecen-2-one (11:1), (Z)-6-tridecen-2-one (13:1), and (Z)-8-pentadecen-2-one (15:1) were identified based on their previously reported mass spectrum $[4,7]$. Even though no mass spectra were available for 2-heptadecenone (17:1), the compound eluted at 15 min (Figure 5) shows a highly similar mass spectral fragmentation pattern to other annotated monosaturated methylketones and had molecular ion peak of $\mathrm{m} / \mathrm{z} 252$ corresponding to the relative molecular mass of 2-heptadecenone. As a negative control, culture of cells just carrying the same vector (pETDuet-1) without an inserted gene was also analyzed, with no 2-methylketones being detected (Figure 5). In the remaining experiment, E. coli C41(DE3) cells expressing SmMKS2-3 also did not produce detectable amounts of 2-methylketones. This could be possibly due to the premature truncation of SmMKS2-3 at the C-terminus resulting in the partial loss of the Hotdog domain required for catalytic activity of this enzyme. 

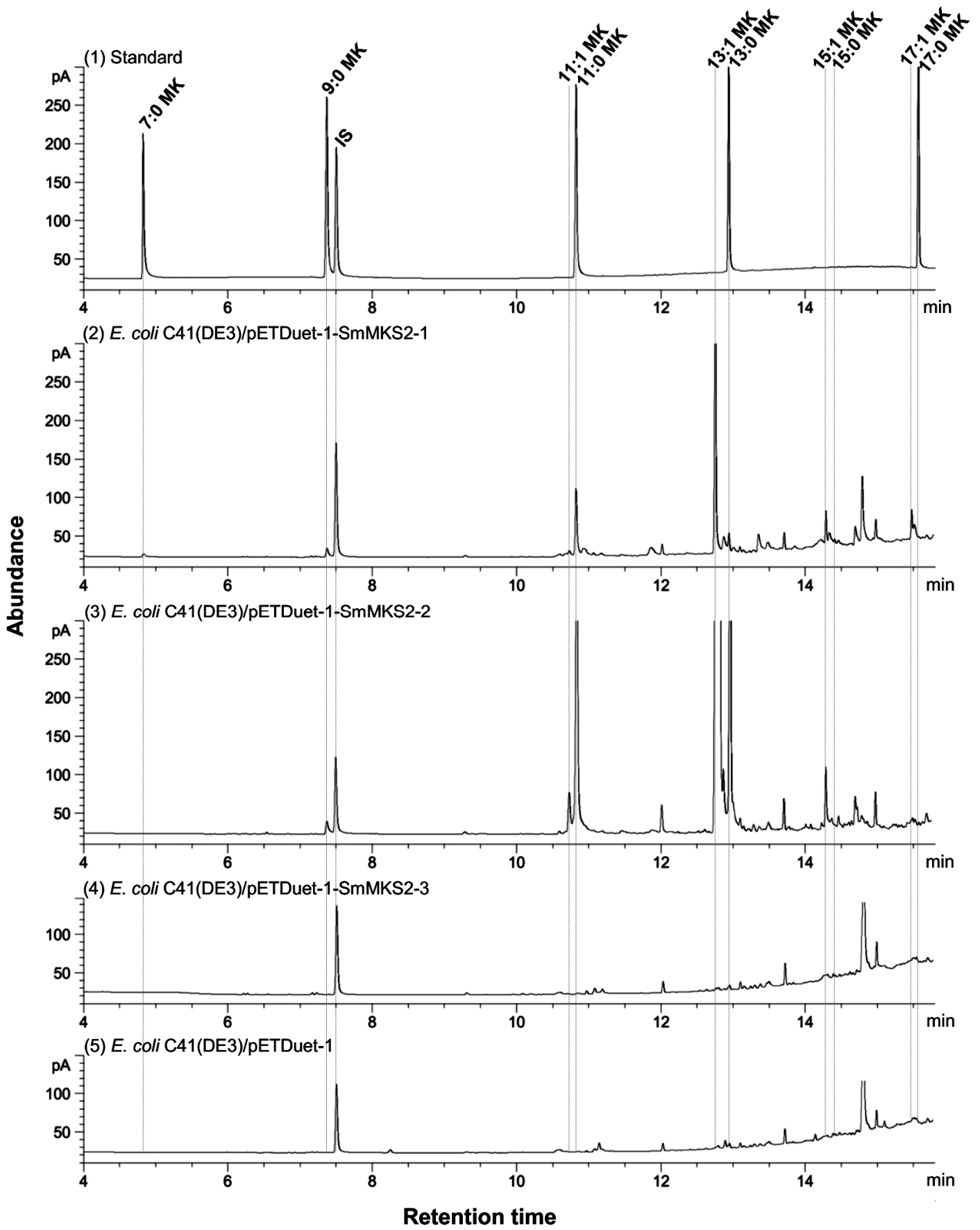

Figure 5. Identification of methylketone products from cell culture of E. coli C41(DE3) expressing three SmMKS2s by gas chromatography-mass spectrometry (GC-MS). 2-Methylketones were identified by GC-MS (see Supplementary File 7), and by comparing their retention times with those of 2-methylketone standards. (1) Authentic methylketone; (2) Cell culture of E. coli C41(DE3) expressing SmMKS2-1; (3) Cell culture of E. coli C41(DE3) expressing SmMKS2-2; (4) Cell culture of E. coli C41(DE3) expressing SmMKS2-3; (5) Cell culture of E. coli C41(DE3) carrying the empty vector (pETDuet-1). 


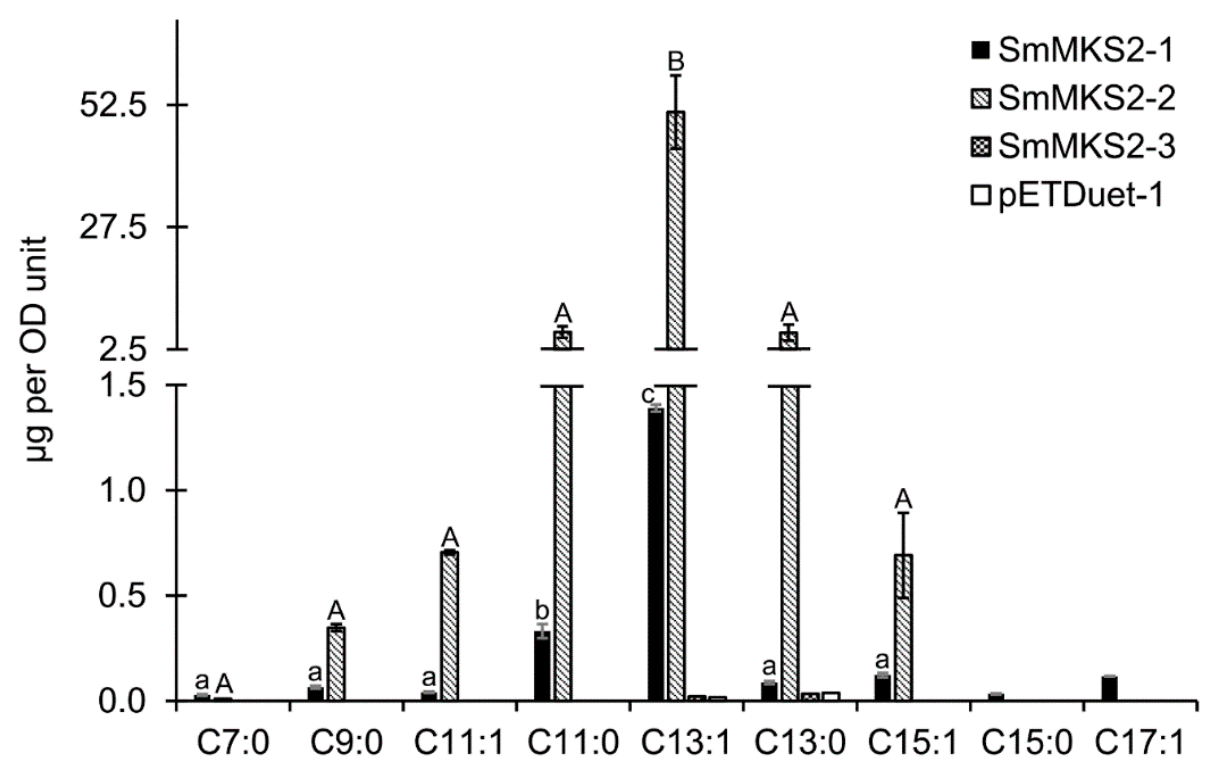

Figure 6. Quantification of 2-methylketones detected following heating the culture of E. coli cells E. coli cells carrying an empty vector, or expressing SmMKS2-1, SmMKS2-2, SmMKS2-3. Cells were grown and media were collected and treated as described in "Materials and Methods." 2-Methylketones, which were derived from $\beta$-ketoacids, were quantified by comparison of peak areas to a linalool internal standard using GC. Values are averages \pm SE calculated from three replicates. Significant differences were assessed by one-way ANOVA followed by Tukey's test. Bars of the same pattern with different letters are significantly different $(p<0.005)$.

\section{Discussion}

\subsection{Biochemical Activities of SmMKS2s}

The sequence-based gene mining discovery approach has led to the identification in eggplant, reported here, of three $\beta$-ketoacyl-ACP thioesterases. The SmMKS2-1, SmMKS2-2, and SmMKS2-3 are closely related to each other, as well as to ShMKS2, which has been demonstrated to be a plastid-targeted $\beta$-ketoacyl-ACP thioesterase [6]. When expressed in E. coli, SmMKS2-1 and SmMKS2-2 proteins showed thioesterase activities towards a variety of $\beta$-ketoacyl-ACPs to produce the corresponding $\beta$-ketoacids, mostly 14:1 $\beta$-ketoacid, whereas SmMKS2-3 showed no detectable activity. Chemical conversion of these compounds to methylketones during the sample treatment process for detection by GC shortens the chain by one carbon relative to the $\beta$-ketoacid (Figures 5 and 6). SmMKS2-1 primarily generates 14:1 $\beta$-ketoacids, with minor $\beta$-ketoacid products ranging from 8-18 carbons in length, whereas SmMKS2-2 has narrower specificity than SmMKS2-1, predominantly producing 12:0, 14:0 and 14:1 $\beta$-ketoacids. However, levels of extractable methylketones, which were derived from $\beta$-ketoacids, in the culture of cells expressing SmMKS2-2 were much higher than in that of cells expressing SmMKS2-1, despite the observation that the expression levels of the two proteins in E. coli were almost the same (Figure 6; Supplementary File 6). Despite their high sequence homology, single Hotdog fold acyl-lipid thioesterases from diverse plant species and taxa exhibit different substrate specificities and are divided into four different ALT groups based on their primary products [9]. SmMKS2-1 and SmMKS2-2 from S. melongena are the most similar to enzymes belonging to the Group 1 ALTs, made up of enzymes that mainly generate 14:1 $\beta$-ketoacid, such as AtALT3 from Arabidopsis thaliana, VvALT1 from Vitis viniferase, MtALT2 from Medicago truncatula, ZmALT2 from Zea mays, etc,,, However, SmMKS2-1 and SmMKS2-2 differed from the enzymes listed in this group in their minor and secondary products. E. coli cells expressing SmMKS2-1 or SmMKS2-2 did not produce 8:0 $\beta$-ketoacids (converted to 7:0 MK) in significant quantities, while this is one of minor products common to the Group 1 MKS2s/ALTs [9]. 
When heterologously expressed in E. coli, SmMKS2-3 does not exhibit thioesterase activity, as the levels of $\beta$-ketoacids in the strain harbouring SmMKS2-3 were barely above the levels that observed in negative control cells carrying the empty vector. One plausible reason for the absence of detectable $\beta$-ketoacids from the cell culture of this recombinant strain is that SmMKS2-3 has a deletion of the last 37 C-terminal amino acid residues and thus loses a part of the single Hotdog fold domain required for catalytic activity of this enzyme (Figure 1).

Based on sequence alignment, we could point out a few interesting differences between either SmMKS2-1 or SmMKS2-2 and known MKS2 sequences from other plants that might help us explore their functional differences upon expression in E. coli. If in vitro characterization of MKS2 remains troublesome, probing this in vivo functional difference using site-directed mutagenesis might be the best feasible analytical approach to predict whether external factors affecting substrate availability such as ACP affinity, fatty acid synthase (FAS) colocalization ... or the steric constraints in the active site cavities of MKS2 enzymes govern functional differences upon expression in E. coli.

\subsection{Induction of SmMKS2-1 by Wounding, MeJA and MeSA Implies a Possible Biological Role for This Gene in Plant Defense}

Plant specialized metabolites with pesticidal properties, such as medium-length 2-methylketones, confer resistance to a wide range of pests in certain crop plants $[29,30]$. As an example, the wild tomato species Solanum habrochaites ssp. glabratum (accession no. PI126449) is highly resistant to various anthropod pests, including spider mites (Tetranychus urticae), aphids (Aphis gossypii), glasshouse whitefly (Trialeurodes vaporariorum), tomato fruitworm (Helicoverpa zea), ten-lined potato beetle (Leptinotarsa decimlineata), tobacco hornworm (Manduca sexta), and tomato leafminer (Tuta absoluta), because of the high contents of 2-tridecanone and other methylketones in the leaves [30,31]. In this study, we identified at least two good candidate genes (SmMKS2-1 and SmMKS2-2) for the in planta production of $\beta$-ketoacids (methylketone precursors) in eggplant, another important member of the genus Solanum. The SmMKS2-1 and SmMKS2-2 proteins are highly similar to the wild tomato methylketone synthase 2, ShMKS2 (67\% and 56\% identical) and expressing the eggplant SmMKS2-1 or SmMKS2-2 gene in E. coli resulted in the production of a wider range of $\beta$-ketoacids in comparison with expressing ShMKS2 [32] (Figures 5 and 6).

In the wild tomato species $S$. habrochaites, $\beta$-ketoacids produced by ShMKS2 are converted to methylketones for defense against pests by a $\beta$-ketoacid decarboxylase (ShMKS1) [33]. Methylketones, however, appear to be present at very low levels in other Solanaceae plant species and in Arabidopsis thaliana $[6,7]$. One possibility is that, in the plant, the $\beta$-ketofatty acids are produced and further metabolized to the other possible final products, such as secondary alcohols, or fatty acid derivatives. Another possibility is that, under normal conditions, MKS2 and other genes putatively associated with methylketone biosynthetic pathway are expressed at low levels compared to those in the wild tomato species [32,34]. This is in line with the observation that herbivore-damaged Arabidopsis plants emitted more 2-pentanone (5:0 MK) than undamaged plants [35]. To assess whether the expression of SmMKS2 genes could be triggered in S. melongena following stress responses, changes in their transcriptional expression in eggplant leaves after wounding or treatment with MeJA or MeSA were analyzed by qRT-PCR. Here we show that artificial wounding, MeJA treatment, or MeSA treatment of intact plants results in higher transcript levels of SmMKS2-1, but neither SmMKS2-2 nor SmMKS2-3 in leaves (Figure 4). The observation that SmMKS2-1 expression in leaves of treated plants was at least twofold higher compared to that in leaves of control plants at $24 \mathrm{~h}$ after treatment (Figure 4), combined with its broad expression pattern (Figure 3), points to a possible function of this gene in plant defense. The question remains whether this induction could lead to a detectable increase in methylketone production in planta. It is interesting to note that methylketone concentrations in the trichomes of transgenic cultivated tomato plants expressing ShMKS2 and ShMKS1 (or only ShMKS2) specifically in the trichomes were 6.5-fold higher than those found in non-transgenic control plants, however still were 100-fold lower than those found in wild tomato trichomes, suggesting that a 
substantial increase in methylketone production requires additional related genes such as fatty acid biosynthesis genes [6]. Extensive genetic and genomic analyses have identified additional genes associated with the high-level production of methylketones in S. habrochaites, such as acetyl-CoA carboxylase (ACC) and malonyl-CoA:ACP transacylase (MCAT). MKS1, ACC, and MCAT showed 355-, 2.7-, and 7.7-fold higher expression, respectively, in the trichomes of the high-MK-containing wild versus in those of low-MK-containing cultivated tomato species [32]. Therefore, it would be worth assessing the transcriptional expression of such genes, in addition to SmMKS2 genes, following mechanical wounding or MeJA/MeSA treatment.

\subsection{Evolution of SmMKS2 Genes}

Plant MKS2/ALT proteins feature a highly conserved C-terminal Hotdog fold domain and an $\mathrm{N}$-terminal transit peptide to direct their transport to the plastid where the acyl-ACP substrates are present $[6,7]$. The biological function of methylketones that are generated by the decarboxylation of $\beta$-ketoacids, products of MKS2 proteins, has been associated with plant resistance to insects $[29,30]$. Homologs of the eggplant SmMKS2s are found in a wide range of plant taxa and they form a distinct clade from the well characterized fatty acyl-ACP thioesterases, FatA and FatB [6,7]. FatA- and FatB-type thioesterases contain two sequential Hotdog fold domains and in a phylogenetic tree, they are grouped according to their substrate specificity, even across plant lineages [36,37]. In contrast, SmMKS2 proteins cluster mainly with other single Hotdog fold fatty acyl-ACP thioesterases from the same or related species (Figure 2). The phylogenetic analysis shown in Figure 2 indicates that a series of gene duplications occurred recently after the split between Arabidopsis and the Solanaceae species investigated here. AtALT1, AtALT2, AtALT3 and AtALT4 were created by such a duplication in Arabidopsis. Examination of the clade of MKS2 genes from the Solanaceae species indicates that duplications and divergence of the original MKS2 gene in this clade occurred within Solanaceae, leading to the first lineage including ShMKS2 and SIMKS2c and a second gene lineage. This second gene lineage further duplicated, forming two new branches: one leading to the gene SmMKS2-2 and the other leading to the ancestral gene of other MKS2s from S. lycopersicum (SIMKS2a and SIMKS2b), S. melongena (SmMKS2-1 and SmMKS2-3), S. tuberosum (StMKS2-1), Capsicum annuum (CaMKS2), and Nicotiana tabacum (NtMKS2-1 and NtMKS2-2).

It has been reported that there are four MKS2-like sequences in the Arabidopsis (Arabidopsis thaliana) and maize (Zea mays) genomes [7,9], three in the cultivated tomato (Solanum lycopersicum) genomes [6], two in the Brachypodium distachyon genomes [9], and one in the wild tomato (Solanum habrochaites), grape (Vitis vinifera) and Cannabis sativa genomes [6,9]. It is noteworthy that in plants with only one MKS2/ALT-like thioesterase, such as S. habrochaites, $V$. vinifera and C. sativa, this enzyme generates 14-carbon $\beta$-ketoacids as a main product along with a wide range of minor products $[6,9]$ and thus might play a broad role in plant defense, while plants with multiple MKS2/ALTs such as Arabidopsis, cultivated tomato and eggplant might have evolved paralogs to play more specific biological roles [7]. SmMKS2-1 possesses the broad expression pattern (Figure 3) and biochemical activity, indicating that it may be involved in more than one biological function in eggplant. SmMKS2-2, however, is more restricted in both expression profiles and substrate preferences, and all products formed by SmMKS2-2 were also produced by SmMKS2-1 (Figures 5 and 6). SmMKS2-1 may have functional overlap with the SmMKS2-2 in tissues where both genes are expressed, but it presumably also has a different role. SmMKS2-1 is the only gene that is expressed in both aerial and root tissues (Figure 3) and upregulated by MeSA, MeJA and wounding (Figure 4), suggesting its possible role in plant defense. SmMKS2-2 was expressed mostly in flowers where it may be involved in production of odor compounds to attract insect pollinators. Although eggplant is generally a self-pollinated crop, in some cases cross-pollination may occur in nature for long-styled flowers [38]. Fatty acid derivatives in general and the odd chain methylketones in particular are often part of floral scent mixtures attractive to visitors of certain flowers $[39,40]$. 


\section{Conclusions}

In this study, we isolated and characterized SmMKS2-1, SmMKS2-2, and SmMKS2-3 from eggplant as putative orthologs of ShMKS2 from wild tomato species. It appears that divergence of both expression profiles and biochemical activity is occurring with different members of this gene group in S. melongena. SmMKS2 genes showed different patterns of expression in the plant, and in response to wounding, methyl jasmonate and methyl salicylate. When being expressed in E. coli, SmMKS2-1 and SmMKS2-2 were functional $\beta$-ketoacyl-ACP thioesterases, producing a wide range of $\beta$-ketoacid, mostly $\beta$-ketomyristic acid (14:1). SmMKS2-2 exhibited narrower substrate preferences but higher activity towards those substrates than SmMKS2-1. The eggplant thioesterases provide opportunities for investigating their products in the crop plant, and their contribution to insect resistance, fragrance and flavor formation, as well as the production of biofuels and renewable chemicals. This finding further highlights how a homology-based gene mining approach in plants can reveal chemical diversity of natural products that might not be exposed by traditional approaches.

Supplementary Materials: The following are available online at http://www.mdpi.com/2073-4425/10/7/549/s1, Supplementary File 1: PCR amplification of SmMKS2-1, SmMKS2-2, and SmMKS2-3 using cDNA template prepared from stems (SmMKS2-1 and SmMKS2-3) and flowers (SmMKS2-2) of S. melongena and gene-specific primers was checked by agarose gel electrophoresis. Lane S: PCR using cDNA template; lane C: PCR without using cDNA template (negative control); laneM: DNA ladder. Supplementary File 2: Nucleotide sequence of SmMKS2-1 and the amino acid sequence of the protein it encodes. Exon sequences are bold with the amino acids sequence above the codons. Supplementary File 3: Nucleotide sequence of SmMKS2-2 and the amino acid sequence of the protein it encodes. Exon sequences are bold with the amino acids sequence above the codons. Supplementary File 4: Nucleotide sequence of SmMKS2-3 and the amino acid sequence of the protein it encodes. Exon sequences are bold with the amino acids sequence above the codons. Underlined sequence corresponds to a 47-insertion in the coding region that causes a frameshift. Supplementary File 5: Evolutionary relationships based on Bayesian inference of the Solanaceae MKS2s and previously reported ALTs from A. thaliana. An HKY85 model was utilized with $4 \gamma$ rate variation categories $(G R+G)$. The chain length was 1,100,000 (4 heated chains with a length of 0.2), and trees were sampled every 200 trees. Branch lengths were unconstrained. Supplementary File 6: Analyses of the recombinant SmMKS2 proteins expressed in the E. coli C41(DE3) strain. Both intracellular soluble (S) and insoluble (I) protein fractions were loaded on sodium dodecyl sulfate polyacrylamide gel electrophoresis (SDS-PAGE) gel, and proteins were stained with Coomassie Brilliant Blue R250. From the left to right: Lanes 1-2 stand for protein fractions prepared from cells transformed with empty vector as a negative control. Lanes 3-4, 6-7 and 7-9 show the expression of SmMKS2-1, SmMKS2-3, and SmMKS2-3 in E. coli C41(DE3) cells, respectively. Lane 5 indicates the molecular weight standards and the arrows indicate the target proteins. Supplementary File 7: Mass spectrometry analysis of 2-pentadecanone and monounsaturated methylketones in Figure 5. Chromatograms are shown in Figure 5 in the text. Supplementary File 8: Synthetic oligonucleotide used in this study. Restriction sites on primers are underlined and primer overhangs are in bold. Start codons are in blue and stop codons in red. "Truncated" refers to the open reading frame (ORF) without the transit peptide coding region. A brief description of what each primer was used for is provided.

Author Contributions: Conceptualization, H.T.A.P. and T.T.H.N.; methodology, V.L.U.K. and H.T.D.T; software, T.C.N; validation, V.L.U.K., N.X.T, T.L.A.D., and T.T.H.N.; formal analysis, V.L.U.K, V.T.T.B., and T.C.N.; investigation, V.L.U.K, V.T.T.B, P.H.H.M, N.X.T., H.T.D.T., and T.T.H.N.; resources, T.L.A.D.; data curation, V.L.U.K. and T.T.H.N.; writing-original draft preparation, V.L.U.K. and T.T.H.N.; writing-review and editing, T.T.H.N.; visualization, V.L.U.K., H.M.D., H.T.A.P., and T.T.H.N.; supervision, H.M.D., H.T.A.P. and T.T.H.N.; project administration, T.T.H.N.; funding acquisition, T.T.H.N. All authors read and approved the final manuscript.

Funding: This research was funded by Vietnam National Foundation for Science and Technology Development (NAFOSTED) under grant number 106-NN.02-2013.35 and by The World Academy of Science (TWAS) under grant number 15-229 RG/BIO/AS_I-FR3240287091 to Thuong Thi Hong Nguyen.

Acknowledgments: The authors wish to thank John G. Turner from University of East Anglia (Norwich, UK) for critical reading of the manuscript.

Conflicts of Interest: The authors declare no conflict of interest.

\section{References}

1. Antonious, G.F. Persistence of 2-tridecanone on the leaves of seven vegetables. Bull. Environ. Contam. Toxicol. 2004, 73, 1086-1093. [CrossRef] [PubMed]

2. Strohalm, H.; Dregus, M.; Wahl, A.; Engel, K.-H. Enantioselective Analysis of Secondary Alcohols and Their Esters in Purple and Yellow Passion Fruits. J. Agric. Food Chem. 2007, 55, 10339-10344. [CrossRef] [PubMed] 
3. Machado, L.L.; Monte, F.J.Q.; Maria da Conceição, F.; de Mattos, M.C.; Lemos, T.L.; Gotor-Fernández, V.; de Gonzalo, G.; Gotor, V. Bioreduction of aromatic aldehydes and ketones by fruits' barks of Passiflora edulis. J. Mol. Catal. B Enzym. 2008, 54, 130-133. [CrossRef]

4. Goh, E.B.; Baidoo, E.E.K.; Keasling, J.D.; Beller, H.R. Engineering of bacterial methyl ketone synthesis for biofuels. Appl. Environ. Microbiol. 2012, 78, 70-80. [CrossRef]

5. Hanko, E.K.R.; Denby, C.M.; Sànchez i Nogué, V.; Lin, W.; Ramirez, K.J.; Singer, C.A.; Beckham, G.T.; Keasling, J.D. Engineering $\beta$-oxidation in Yarrowia lipolytica for methyl ketone production. Metab. Eng. 2018, 48, 52-62. [CrossRef]

6. Yu, G.; Nguyen, T.T.H.; Guo, Y.; Schauvinhold, I.; Auldridge, M.E.; Bhuiyan, N.; Ben-Israel, I.; Iijima, Y.; Fridman, E.; Noel, J.P.; et al. Enzymatic Functions of Wild Tomato Methylketone Synthases 1 and 2. Plant Physiol. 2010, 154, 67-77. [CrossRef]

7. Pulsifer, I.P.; Lowe, C.; Narayaran, S.A.; Busuttil, A.S.; Vishwanath, S.J.; Domergue, F.; Rowland, O. Acyl-lipid thioesterase1-4 from Arabidopsis thaliana form a novel family of fatty acyl-acyl carrier protein thioesterases with divergent expression patterns and substrate specificities. Plant Mol. Biol. 2014, 84, 549-563. [CrossRef]

8. Kornberg, A.; Ochoa, S.; Mehler, A.H. Spectrophotometric studies on the decarboxylation of $\beta$-keto acids. J. Biol. Chem. 1948, 174, 159-172.

9. Kalinger, R.S.; Pulsifer, I.P.; Rowland, O. Elucidating the substrate specificities of acyl-lipid thioesterases from diverse plant taxa. Plant Physiol. Biochem. 2018, 127, 104-118. [CrossRef]

10. Sato, S.; Tabata, S.; Hirakawa, H.; Asamizu, E.; Shirasawa, K.; Isobe, S.; Kaneko, T.; Nakamura, Y.; Shibata, D.; Aoki, K.; et al. The tomato genome sequence provides insights into fleshy fruit evolution. Nature 2012, 485, 635-641.

11. Xu, X.; Pan, S.; Cheng, S.; Zhang, B.; Mu, D.; Ni, P.; Zhang, G.; Yang, S.; Li, R.; Wang, J.; et al. Genome sequence and analysis of the tuber crop potato. Nature 2011, 475, 189-195. [PubMed]

12. Hirakawa, H.; Shirasawa, K.; Miyatake, K.; Nunome, T.; Negoro, S.; Ohyama, A.; Yamaguchi, H.; Sato, S.; Isobe, S.; Tabata, S.; et al. Draft genome sequence of eggplant (Solanum melongena L.): The representative Solanum species indigenous to the old world. DNA Res. 2014, 21, 649-660. [CrossRef] [PubMed]

13. Qin, C.; Yu, C.; Shen, Y.; Fang, X.; Chen, L.; Min, J.; Cheng, J.; Zhao, S.; Xu, M.; Luo, Y.; et al. Whole-genome sequencing of cultivated and wild peppers provides insights into Capsicum domestication and specialization. Proc. Natl. Acad. Sci. USA 2014, 111, 5135-5140. [CrossRef] [PubMed]

14. Kim, S.; Park, M.; Yeom, S.I.; Kim, Y.M.; Lee, J.M.; Lee, H.A.; Seo, E.; Choi, J.; Cheong, K.; Kim, K.T.; et al. Genome sequence of the hot pepper provides insights into the evolution of pungency in Capsicum species. Nat. Genet. 2014, 46, 270-278. [CrossRef]

15. Sierro, N.; Battey, J.N.D.; Ouadi, S.; Bakaher, N.; Bovet, L.; Willig, A.; Goepfert, S.; Peitsch, M.C.; Ivanov, N.V. The tobacco genome sequence and its comparison with those of tomato and potato. Nat. Commun. 2014, 5, 3833. [CrossRef] [PubMed]

16. Aubriot, X.; Knapp, S.; Syfert, M.M.; Poczai, P.; Buerki, S. Shedding new light on the origin and spread of the brinjal eggplant (Solanum melongena L.) and its wild relatives. Am. J. Bot. 2018, 105, 1175-1187. [CrossRef]

17. Weese, T.L.; Bohs, L. Eggplant origins: Out of Africa, into the Orient. Taxon 2010, 59, 49-56. [CrossRef]

18. Fowler, J.H.; Narvaez-Vasquez, J.; Aromdee, D.N.; Pautot, V.; Holzer, F.M.; Walling, L.L. Leucine Aminopeptidase Regulates Defense and Wound Signaling in Tomato Downstream of Jasmonic Acid. Plant Cell Online 2009, 21, 1239-1251. [CrossRef]

19. Falara, V.; Alba, J.M.; Kant, M.R.; Schuurink, R.C.; Pichersky, E. Geranyllinalool Synthases in Solanaceae and Other Angiosperms Constitute an Ancient Branch of Diterpene Synthases Involved in the Synthesis of Defensive Compounds. Plant Physiol. 2014, 166, 428-441. [CrossRef]

20. Ament, K.; Van Schie, C.C.; Bouwmeester, H.J.; Haring, M.A.; Schuurink, R.C. Induction of a leaf specific geranylgeranyl pyrophosphate synthase and emission of (E,E)-4,8,12-trimethyltrideca-1,3,7,11-tetraene in tomato are dependent on both jasmonic acid and salicylic acid signaling pathways. Planta 2006, 224, 1197-1208. [CrossRef]

21. Yao, H.; Guo, L.; Fu, Y.; Borsuk, L.A.; Wen, T.-J.; Skibbe, D.S.; Cui, X.; Scheffler, B.E.; Cao, J.; Emrich, S.J.; et al. Evaluation of five ab initio gene prediction programs for the discovery of maize genes. Plant Molecular Biology 2005, 57, 445-460. [CrossRef]

22. Kumar, S.; Stecher, G.; Li, M.; Knyaz, C.; Tamura, K. MEGA X: Molecular evolutionary genetics analysis across computing platforms. Mol. Biol. Evol. 2018, 35, 1547-1549. [CrossRef] 
23. Pfaffl, M.W. A new mathematical model for relative quantification in real-time RT-PCR. Nucleic Acids Res. 2001, 29, e45. [CrossRef]

24. Laemmli, U.K. Cleavage of structural proteins during the assembly of the head of bacteriophage T4. Nature 1970, 227, 680-685. [CrossRef]

25. Schägger, H.; von Jagow, G. Tricine-sodium dodecyl sulfate-polyacrylamide gel electrophoresis for the separation of proteins in the range from 1 to $100 \mathrm{kDa}$. Anal. Biochem. 1987, 166, 368-379. [CrossRef]

26. Benning, M.M.; Wesenberg, G.; Liu, R.; Taylor, K.L.; Dunaway-Mariano, D.; Holden, H.M. The three-dimensional structure of 4-hydroxybenzoyl-CoA thioesterase from Pseudomonas sp. strain CBS-3. J. Biol. Chem. 1998, 273, 33572-33579. [CrossRef]

27. Cantu, D.C.; Chen, Y.; Reilly, P.J. Thioesterases: A new perspective based on their primary and tertiary structures. Protein Sci. 2010, 19, 1281-1295. [CrossRef]

28. Angelini, A.; Cendron, L.; Goncalves, S.; Zanotti, G.; Terradot, L. Structural and enzymatic characterization of HP0496, a YbgC thioesterase from Helicobacter pylori. Proteins Struct. Funct. Genet. 2008, 72, 1212-1221. [CrossRef]

29. Antonious, G.F.; Dahlman, D.L.; Hawkins, L.M. Insecticidal and Acaricidal Performance of Methyl Ketones in Wild Tomato Leaves. Bull. Environ. Contam. Toxicol. 2003, 71, 400-407. [CrossRef]

30. Gonçalves, M.I.F.; Maluf, W.R.; Gomes, L.A.A.; Barbosa, L.V. Variation of 2-tridecanone level in tomato plant leaflets and resistance to two mite species (Tetranychus sp.). Euphytica 1998, 104, 33-38.

31. Williams, W.G.; Kennedy, G.G.; Yamamoto, R.T.; Thacker, J.D.; Bordner, J. 2-Tridecanone: A naturally occurring insecticide from the wild tomato Lycopersicon hirsutum f. glabratum. Science 1980, 207, 888-889. [CrossRef]

32. Ben-Israel, I.; Yu, G.; Austin, M.B.; Bhuiyan, N.; Auldridge, M.; Nguyen, T.; Schauvinhold, I.; Noel, J.P.; Pichersky, E.; Fridman, E. Multiple Biochemical and Morphological Factors Underlie the Production of Methylketones in Tomato Trichomes. Plant Physiol. 2009, 151, 1952-1964. [CrossRef]

33. Auldridge, M.E.; Guo, Y.; Austin, M.B.; Ramsey, J.; Fridman, E.; Pichersky, E.; Noel, J.P. Emergent Decarboxylase Activity and Attenuation of $\alpha / \beta$-Hydrolase Activity during the Evolution of Methylketone Biosynthesis in Tomato. Plant Cell 2012, 24, 1596-1607. [CrossRef]

34. Yu, G.; Pichersky, E. Heterologous Expression of Methylketone Synthase1 and Methylketone Synthase2 Leads to Production of Methylketones and Myristic Acid in Transgenic Plants. Plant Physiol. 2014, 164, 612-622. [CrossRef]

35. Van Poecke, R.M.P.; Posthumus, M.A.; Dicke, M. Herbivore-induced volatile production by Arabidopsis thaliana leads to attraction of the parasitoid Cotesia rubecula: Chemical, behavioral, and gene-expression analysis. J. Chem. Ecol. 2001, 27, 1911-1928. [CrossRef]

36. Mayer, K.M.; Shanklin, J. Identification of amino acid residues involved in substrate specificity of plant acyl-ACP thioesterases using a bioinformatics-guided approach. BMC Plant Biol. 2007, 7, 1. [CrossRef]

37. Jones, A.; Davies, H.M.; Voelker, T.A. Palmitoyl-Acyl Carrier Protein (ACP) Thioesterase and the Evolutionary Origin of Plant Acyl-ACP Thioesterases. Plant Cell 2007, 7, 359.

38. Choudhary, B.; Gaur, K. The development and regulation of Bt Brinjal in India (Eggplant/Aubergine). ISAAA Brief 382009.

39. Knudsen, J.T.; Tollsten, L.; Bergström, L.G. Floral scents-a checklist of volatile compounds isolated by head-space techniques. Phytochemistry 1993, 33, 253-280. [CrossRef]

40. Flath, R.A.; Ohinata, K. Volatile components of the orchid Dendrobium superbum Rchb. f. J. Agric. Food Chem. 1982, 30, 841-842. [CrossRef]

(C) 2019 by the authors. Licensee MDPI, Basel, Switzerland. This article is an open access article distributed under the terms and conditions of the Creative Commons Attribution (CC BY) license (http://creativecommons.org/licenses/by/4.0/). 